\title{
PERAN DAN FUNGSI PENELITI DWI BAHASA (BILINGUAL): STUDI KASUS : WAWANCARA DENGAN INFORMAN DI DESA JATILUWIH, BALI INDONESIA
}

\author{
Gde Indra Bhaskara \\ Fakultas Pariwisata Universitas Udayana \\ Email: gbhaskara@unud.ac.id
}

\begin{abstract}
This study discusses the process of translating and adapting an interview content in Indonesian or regional (in this case Bali) into English in a Tourism study. This process certainly cannot be overlooked because of differences in Indonesian language and culture that are quite significant towards English and western culture. Therefore, this research offers a new insight in how a bilingual researcher takes action hence a translated interview will not lose its essence when it is analysed. The researcher used Computer Assisted/Aided Qualitative Data Analysis Software (CAQDAS) namely Nvivo in analyzing interviews from informants. In this study it also explains about how the meaning of the contents of an interview lose the meaning at the analysis phase when error occurs.
\end{abstract}

Keywords : bilingual, indonesian, bali, english, interview, research, researcher

\section{Pendahuluan}

Pada umumnya jurnal artikel penelitian terhadap informan yang tidak memakai Bahasa Inggris cenderung tidak menjelaskan proses terjemahan Bahasa asli para informannya Umumnya para peneliti ini tidak mendefinisikan secara detail metode penerjemahan yang digunakan dalam studi mereka (Esposito 2001). Akibatnya, para peneliti ini cenderung gagal untuk memperlihatkan obyektifitas penelitiannya ketika ditanyakan apakah terjemahan dari para informannya sudah benar jika dialihbahasakan ke dalam Bahasa Inggris (Larkin et al. 2007). 
Seperti yang dikatakan oleh Tsai et al. (2012), terjemahan adalah salah satu faktor yang mempengaruhi terhadap keakuratan penelitian lintas budaya dan penelitian kualitatif lintas bahasa. Hal ini diakibatkan karena ada beberapa konsep-konsep yang tidak selalu sama yang ada di seluruh budaya dan bahasa di dunia. Oleh sebab itu, penerjemah harus kreatif dalam menemukan cara untuk menyampaikan konsepkonsep dari satu bahasa ke bahasa lain (ibid).

Topik terjemahan dan tafsir mendapat perhatian dalam literatur penelitian karena banyaknya studi yang dilakukan oleh lembaga-lembaga di negara-negara berbahasa Inggris dengan mata pelajaran berbahasa non-Inggris. Beberapa penulis telah menyatakan pendapat mereka tentang pertimbangan etis yang dapat muncul dari kondisi seperti itu. Sebagai contoh, sebuah studi Uni Eropa dilakukan pada anak dan remaja imigran dimana transkripsi dari bahasa aslinya (Portugis, Swedia atau Yunani) yang diproses dalam dua budaya dan bahasa yang berbeda. Penelitian ini dipertanyakan karena apakah peneliti yang merupakan penutur asli Bahasa Inggris menganilisis makna atau kata demi kata (Redmond 2003 dikutip oleh Shklarov 2007).

\section{Landasan Teori dan Konsep}

Sebuah studi tentang perilaku dan kesehatan remaja dilakukan oleh tim peneliti multikultural menghasilkan perspektif yang berbeda selama tahap interpretasi (Michaud et al. 2001). Contoh lain adalah studi imigran Korea oleh Choi et al. (2012), yang menimbulkan masalah kemampuan penerjemah untuk memahami budaya dan bahasa dari imigran dan isu yang khusus yang dikenal sebagai back translation/terjemahan kembali.

Sebuah back translation/terjemahan kembali (menerjemahkan bahasa ibu ke dalam bahasa inggris dan kemudian diterjemahkan kembali ke dalam bahasa ibu) telah dianggap sebagai validasi dan verifikasi teknik terbaik untuk memastikan keakuratan 
terjemahan, berdasarkan sumber asli dari transkripsi (buletin). Ide terjemahan kembali adalah untuk memverifikasi apakah terjemahan mewakili semua aspek aslinya (Brislin 1970; Andriesen 2008). Isu terjemahan kembali umumnya terkait dengan penelitian menggunakan kuesioner sebagai metode pengumpulan data (Brislin 1970; Micahud et al, 2001; Andriesen 2008). Jika pertanyaan-pertanyaan dalam kuesioner tidak diterjemahkan secara tepat dari aslinya, adanya kekhawatiran dimana jawaban tidak akan mewakili hasil yang akurat (Andriesen 2008). Back translation/terjemahan kembali bekerja secara efektif dan akurat dalam kondisi dimana sumber dan target bahasa memiliki struktur serupa. Misalnya, Bahasa Denmark, Prancis, Jerman, Italia dan Spanyol memiliki struktur mirip dengan Bahasa Inggris karena mereka diklasifikasikan dalam kelompok bahasa Indo-Eropa (Brislin 1970). Selain itu, back translation/terjemahan kembali tidak seakurat daripada numeric translation/ perhitungan matematika karena simbol verbal (kata-kata) yang tidak terbatas, sedangkan simbol matematika masih bersifat jelas dan tepat. Tambahan pula terjemahan bukan ilmu karena, dalam ilmu, faktor yang sama dan aspek yang sama akan menciptakan hasil yang konstan. Seperti diasumsikan oleh Regmi et al. (2010), sulit untuk mengembangkan transkripsi yang tepat dan ringkas karena makna dan kesetaraan yang tepat, tidak ada. Jones dan Kay (1992) menyatakan, penyebab dari hal ini adalah tidak semua terminologi dapat diterjemahkan secara bebas karena tidak semua konsep bersifat sama dan universal. "Proses penterjemahan adalah lebih dari sekedar mengalihkan kata-kata dari satu bahasa ke bahasa lain" (Temple 2002, h.846).

Masalah utama tentang proses terjemahan adalah kesetaraan karena makna katakata diasosiakan dengan budaya yang harus diperhatikan dalam proses terjemahan (Hunt dan Bhopal 2004). Squires (2009) menyarankan, untuk memastikan terjemahan memiliki makna setara dan tetap menjaga relevansi budaya dari kedua bahasa aslinya (non-Inggris) dan bahasa studi (Inggris), dimana ini adalah masalah mendasar untuk penelitian lintas bahasa. Dalam terjemahan studi lintas budaya, budaya dan interpretasi 
memainkan bagian yang sangat penting karena terjemahan bahasa bukan suatu perihal linguistik sederhana.

Seperti yang disarankan oleh Choi et al. (2012), memahami kondisi budaya pemahaman dalam konteks dalam suatu fenomena adalah sangat penting. Kedekatan peneliti dengan budaya dari populasi responden akan dapat memberi hasil yang signifikan pada pemahaman tentang hasil penelitian (Munet-Vilaro 1988). Misalnya, sebagai orang Bali, peneliti akrab dengan istilah-istilah seperti 'banjar', 'organisasi kesejahteraan keluarga' dan 'musyawarah mufakat. Sebuah studi yang dilakukan oleh Tsai et al. (2004) tentang penggunaan feses pengujian darah samar (FOBT) pada peserta yang berkewarganegaraan Amerika keturunan China menunjukkan keterlibatan peneliti dari latar belakang budaya yang sama dengan peserta menghasilkan analisis lebih dalam dan lebih kaya yang tidak hanya menggambarkan situasi saat ini, tetapi juga bisa memprediksi tren masa depan. Temple dan Young (2004) menyatakan, analisis data lintas bahasa terbaik adalah yang dilakukan oleh peneliti bilingual karena mereka mampu menginterpretasikan terjemahannya secara sendiri.

Seorang peneliti bilingual/dwi bahasa memiliki banyak kemampuan untuk mengenali dan memahami masalah, sebagai hasil dari atau pemahamannya tentang budaya yang dia teliti dan pemahaman yang lebih tentang lintas bahasa (Shklarov 2007). Seperti yang disarankan oleh Birblii (2000), seni menerjemahkan membutuhkan suatu keseimbangan antara keterampilan linguistik dan kedalaman pengetahuan akan budaya responden/informan dan ini berdampak langsung pada kepercayaan dari peneliti. Oleh karena itu, selain keterampilan bahasa, memiliki latar belakang budaya yang sama dengan informan yang diwawancari dianggap sebagai keuntungan dalam menghasilkan transkripsi yang tepat dan bermakna (Temple 2002; Lee et al 2007). Sebuah studi oleh Chung (2000) menunjukkan pentingnya memahami konteks budaya dalam terjemahan. Sebuah kalimat sederhana dalam bahasa Indonesia dapat membawa beberapa arti dalam bahasa Inggris, seperti yang dijelaskan dalam kalimat ini:

415 JUMPA Volume 05, Nomor 02, Januari 2019 
Ali tidak jadi membeli buku (Indonesian)

Ali not finished buy book (terjemahan kata demi kata ke Inggris)

'Ali didn't buy any book(s)/there was a book that Ali didn't buy (terjemahan yang paling mewakili)

Namun, penutur bahasa Indonesia bisa menafsirkan terjemahan yang benar di atas ke dalam dua kondisi. Dalam kondisi A, Ali sangat miskin, ia pergi ke sebuah toko buku yang ingin membeli buku tapi dia tidak mampu membelinya. Dalam kondisi B, Ali sangat kaya, dia membeli semua buku yang dia inginkan tapi satu buku luput dari perhatiannya karena terselip di antara beberapa surat kabar. Oleh karena itu, ia membeli semua buku, tapi tidak buku itu (Chung 2000).

Dalam penelitian ini, peneliti mengadopsi peran ganda seorang peneliti bilingual/dwi bahasa, berfungsi sebagai peneliti dan penerjemah di analisis dengan monolingual, non-berbahasa Inggris dari informan yang diteliti. bahasa pertama peneliti adalah Indonesia, Bali merupakan yang kedua dan Inggris adalah ysng ketiga. Meskipun kemampuan bahasa Inggris-nya kurang dari kemampuannya berbahasa Indonesia, peneliti memiliki kelebihan untuk tidak dikategorikan sebagai peneliti bilingual yang 'membeku dalam waktu'. Istilah 'membeku dalam waktu' diperkenalkan oleh Temple dan Edward (2002) untuk menggambarkan para peneliti blingual yang telah tinggal di negara-negara barat untuk waktu yang lama dan di mana bahasa mereka, budaya dan nilai-nilai mungkin berbeda dari budaya dan bahasa negara asal mereka. Perbedaan ini disebabkan oleh perubahan dalam budaya asal mereka dan bahasa menyebabkan mereka tidak tahu kata-kata baru dan terminologi yang telah muncul dalam bahasa ibu mereka karena mereka meninggalkan negara asal mereka dalam waktu yang lama (ibid). 
Keuntungan lain untuk menjadi seorang peneliti bilingual adalah kemampuan untuk memeriksa kualitas data yang diterjemahkan dan untuk memastikan terjemahan tersebut dilakukan dengan tepat. Seperti dikemukakan oleh Tsai et al. (2004), analisis data yang diterjemahkan dapat kehilangan pemahaman asli dari informan asli karena telah dimodifikasi oleh penerjemah melalui kalimat dan kata kata dari si penerjemah. Namun, Bhopal (1995) menyatakan, "Untuk orang dalam/lokal, risiko memodifikasikan data secara subyektif sangat besar, karena kedekatan dengan obyek yang diteliti dan akan mempengaruhi data yang dihasilkan" (hal.161). Dikatakan bahwa kedekatan penutur asli mungkin membuat dia mengabaikan ide-ide yang unik yang hanya mampu diidentifikasi oleh individu yang berasal dari kelompok etnis / budaya lainnya.

Dalam kondisi tertentu, peneliti dalam penilitiannya di Desa Jatiluwih harus memodifikasi kalimat dalam paragraf atau membuat beberapa perubahan untuk mepertahankan makna, pada saat yang sama, membuat terjemahan tata bahasa yang benar dalam Bahasa Inggris. Peneliti bisa menambahkan dan / atau mengubah katakata, frasa dan kalimat untuk memastikan bahwa wawancara mengalir dengan baik dan bahwa makna yang terkandung sama sebelum dan sesudah diterjemahkan. Tidak seperti Bahasa Inggris, kata kerja Indonesia tidak mengenal kata kerja berdasarkan waktu lampau, sekarang dan akan datang; Oleh karena itu, bahasa Indonesia tidak menentukan apakah tindakan itu terjadi di masa lalu, yang terjadi pada saat ini atau yang akan terjadi di masa depan. Dalam rangka untuk mengidentifikasi ketika aksi berlangsung, Penutur berbahasa Indonesia biasanya menggunakan kata-kata temporal, seperti 'sekarang' dan 'segera' tanpa mengubah kata kerja setelah kejadian atau tindakan (Boroditsky et al. 2002). Oleh karena itu, dalam penelitian ini, peneliti ditantang dengan tugas menciptakan terjemahan berdasarkan makna-bukan kata-demikata terjemahan karena Bahasa Indonesia berbeda dari Bahasa Inggris dalam beberapa aspek. Misalnya, kata benda tidak berubah berdasarkan jumlah; tidak ada artikel langsung dan tidak langsung; kata ganti orang 'dia' bisa berarti 'he (laki-laki)' atau 'she 417 JUMPA Volume 05, Nomor 02, Januari 2019 
(wanita). Selain itu, ada kesulitan lain bagi penutur Indonesia karena kata-kata dalam

Bahasa Indonesia tidak memiliki kesamaan secara struktural dengan bahasa Inggris (Yong 2005). Kalimat pasif jarang digunakan dalam berbicara Bahasa Indonesia dan gerund dan infinitif tidak ada dalam Bahasa Indonesia (Yong 2005).

\section{Metode Penelitian}

Penelitian ini melibatkan 60 informan untuk mengetahui peran serta mereka di dalam nominasi Warisan Budaya Dunia dan juga keterlibatan dalam pengelolaan Desa Jatiluwih sebagai Daerah Tujuan Wisata. Dalam penelitian ini menggunakan Quota Sampling, Purposive Sampling dan Time and Place Sampling. Quota Sampling untuk memastikan bahwa informan yang diwawancara mewakili seluruh elemen masyarakat yang ada di Desa Jatiluwih Bali. Purposive Sampling berdasarkan tujuan diadakannya wawancara, dalam hal ini pada umumnya orang yang dianggap memberikan informasi yang lengkap, jelas dan terperinci. Time and Place Sampling dipergunakan untuk mewawancarai informan yang ditemukan pada waktu dan tempat tertentu, misalnya pada saat menunggu mobil pariwisata lewat (khusus untuk informan yang menjaga pintu masuk). Semua wawancara direkam menggunakan sony voice recorder yang kemudian dibuat transkripsinya dan ditransefer ke Software Nvivo 9 untuk decoding. Pengcodingan dilakukan dalam tiga tahap, tahap pertama adalah mencoding kalimat demi kalimat dengan maksud agar pengcodingan tidak terpengaruh oleh teori yang mendasari penelitian, tahap kedua pengcodingan dilakukan untuk mendapatkan tema yang sama, dan yang ketiga terakhir disesuaikan dengan teori yang mendasari. 


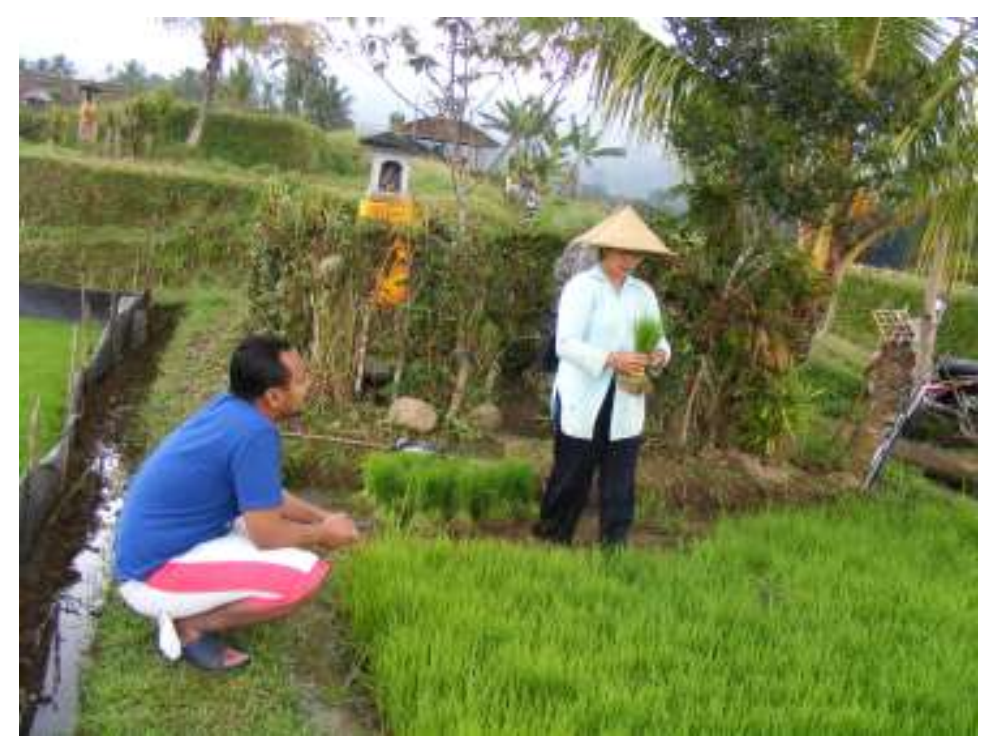

Gambar 1. Peneliti mewawancari petani di sawah Menggunakan bahasa Indonesia Sumber : Dokumentasi peneliti (2018)

\section{Pembahasan}

Dalam penelitian ini, peneliti membiarkan transkripsi wawancara dalam bahasa asli (Indonesia) karena membiarkan transkripsi dalam bahasa asli menghindari kehilangan makna aslinya ketika mereka dikodekan (coding). Belajar dari ketidakakuratan selama fase pertama dari pilot study, peneliti menerjemahkan wawancara ke dalam Bahasa Inggris terlebih dahulu dan baru kemudian dicodekan (coding) dimana hasilnya untuk setiap wawancara menjadi identik atau mirip. Peneliti kemudian menyadari bahwa beberapa frase Indonesia yang diterjemahkan ke dalam kata-kata Bahasa Inggris tidak mencerminkan makna sebenarnya. Dengan menerjemahkan wawancara sebelum analisis coding, peneliti telah mengubah makna dari data temuan yang asli. Dengan demikian, dalam penelitian ini, peneliti mengcoding wawancara dari bahasa asli; Namun, label untuk coding dalam Bahasa Inggris. Tujuan menggunakan bahasa Inggris ketika label untuk pengkodean adalah untuk memudahkan peneliti selama analisis kualitatif. Proses pengulangan, perbaikan 
dan recoding selama analisis dengan NVivo harus sejalan dengan latar belakang teoritis. Jadi, dengan menggunakan label coding dalam Bahasa Inggris akan memastikan label coding dan landasan teori sesuai untuk menghasilkan hasil berdasarkan pendekatan ilmiah.

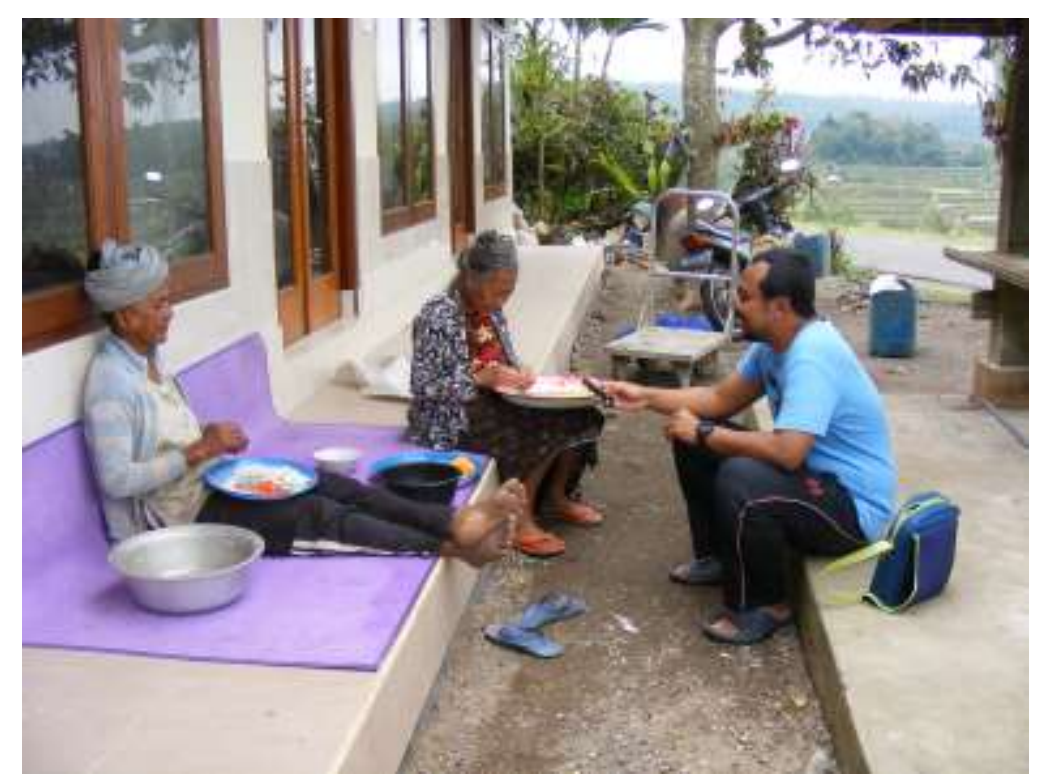

Gambar 2. Peneliti mewawancarai informan menggunakan Bahasa Bali Sumber : Dokumentasi Peneliti (2018)

Peneliti benar-benar menyadari konsekuensi etis dari peran seorang penelitipenerjemah bilingual yang secara aktif terlibat dalam memperoleh data mentah, pada saat yang sama, menerjemahkan data ke dalam bahasa Inggris. Seperti yang dijelaskan oleh Shklarov 2007, dua pandangan bertentangan dari peran seorang peneliti bilingual adalah peran seorang penerjemah yang jujur dan dihadapkan pada peran aktif dari seorang peneliti yang inovatif. Oleh karena itu, masalah utama bagi para peneliti bilingual yaitu kejujuran karena peneliti bilingual menambil dua peran yaitu sebagai peneliti dan penerjemah. 


\section{Simpulan dan Saran}

Peneliti dua bahasa mempunyai tanggungjawab yang signifikan terhadap bagaimana suatu wawancara dari informan diterjemahkan tanpa mengurangi esensi dari sumber aslinya. Ini jelas tidak mudah, karena menerjemahan suatu ekspresi dan kata-kata sangat berhubungan dengan seberapa jauh bahasa dan sekaligus budaya itu berbeda dengan bahasa Inggris dan budaya barat. Untuk sebab itu, peneliti menyertakan bagaimana suatu wawancara direkam, kemudian dianalisis ke beberapa tahap dan menggunakan pilot study. Proses wawancara, penerjemahan dan Analisa dijelaskan secara terperinci agar diketahui bahwa informasi dapat dipertanggungjawabkan dan bukan olahan subyektif dari peneliti. Sebagai peneliti dwi bahasa, peneliti menyadari bahwa kejujuran dan integritas adalah hal yang paling mendasar yang tidak dapat ditawar, Peneliti berharap, melalui penelitian ini, penelitipeneliti yang melakukan studinya di luar negeri khususnya di bidang pariwisata dan ilmu sosial memperhatikan isu translation ini. Pada umumnya peneliti Indonesia yang melakukan studi di luar negeri cenderung mengabaikan tentang bagaimana suatu informasi yang di dapat dalam Bahasa Daerah maupun Bahasa Indonesia yang untuk kemudian diterjemahkan ke dalam Bahasa Inggris.

\section{Daftar Pustaka}

Andriesen, S., 2008. Benefiting from back translations. Clinical Trial Management 16-20 [online]. Leiden: Medilingua. Available from: http://www.medilingua.com/pdf/BackTranslationsICTSummer\%202008.pdf [Accessed 1 April 2013].

Brislin, R.W. 1970. Back-translation for cross-cultural research. Journal of Cross-Cultural Psychology [online], 1 (3), 185-216.

Choi, J. Kushner, K.E. Mill, J. Lai, D.W.L., 2012. Understanding the language, the culture, and the experience: translation in cross-cultural research. International Journal of Qualitative Methods [online], 11 (5), 652-665. 
Esposito, N., 2001. From meaning to meaning: the influence of translation techniques on non-English focus group research. Qualitative Health Research [online], 11 (4), 568-579.

Hunt, S. M. Bhopal, R., 2004. Self report in clinical and epidemiological studies with non-English speakers: the challenge of language and culture. Journal of Epidemiology and Community Health [online], 58, 618-622.

Jones, E. Kay, M. 1992. Instrumentation in cross-culture research. Nursing Research [online], 41 (3), 186-188.

Larkin, P. J. Dierckx de Casterlé, B. Schotsmans, P., 2007. Multilingual translation issues in qualitative research: Reflections on a metaphorical process. Qualitative Health Research [online], 17 (4), 468-476.

Michaud, P. Blum, R. W. Slap, G. B., 2001. Cross-cultural surveys of adolescent health and behaviour: Progress and problems. Social Sciece and Medicine [online], 53 (9), 1237-1246.

Munet-Vilaró, F. 1988. Technical notes. The challenge of cross-cultural nursing research. Western journal of nursing research [online], 10 (1), 112.

Regmi, K. Naidoo, J. Pilkington, P., 2010. Understanding the processes of translation and transliteration in qualitative research. International Journal of Qualitative Methods [online], 9 (1), 16-26.

Shklarov, S., 2007. Double vision uncertainty: The bilingual researcher and the ethics of cross language research. Qualitative Health Research [online]. 17 (4), 529-538.

Squires, A., 2009. Methodological challenges in cross-language qualitative research: a research review. International Journal of Nursing Studies [online], 46 (2), 277-287.

Tsai, J.H.C. Choe, J.H. Lim, J.M.C. Acorda, E. Chan, N.L. Taylor, V.M. Tu, S.P., 2004. Developing culturally competent health knowledge: issues of data analysis of cross-cultural, cross-language qualitative research. International Journal of Qualitative Methods [online], 3 (4), 16-27.

Yong, J. Y., 2005. Malay/Indonesian speakers. In: Swain, M. Smith, B., eds. Learner English: A teacher's guide to interference and other problems, New York: Cambridge University Press, 279-295. 


\section{Profil Penulis}

Gde Indra Bhaskara SST. Par, MSc., Ph.D adalah dosen tetapUniversitas Udayana kelahiran 19 Desember 1978. Beliau menamatkan sekolahnya di STP Nusa dua Bali pada tahun 2001 dan untuk kemudian melanjutkan program Master ke Bournemouth University pada tahun 2002-2004. Sekembalinya dari Inggris, beliau bekerja pada HES Global, sebuah perusahaan terkemuka yang memfokuskan dalam mencari dan menempatkan eksekutif/pemimpin-pemimpin perusahaan di seluruh dunia pada industri Perhotelan dan jasa, pada kurun waktu 2004-2006. Pada periode berikutnya, beliau mengajar di Manajemen Perhotelan Indonesia yang dikenal dengan nama MAPINDO. Menghabiskan waktu dua tahun disana, pada tahun 2008 diterima di Universitas Udayana sebagai dosen tetap. Hanya berkesempatan mengajar selama dua semester setelah diangkat menjadi dosen tetap di Universitas Udayana, beliau mendapatkan beasiswa untuk melanjutkan pendidikan S3 ke Bournemouth University di tahun 2010. 